\title{
Symmetric RAFT-agent for synthesizing multiblock copolymers with different activated monomers
}

\author{
Lena Petrozziello, ${ }^{1,2}$, Matthias Häußler², Christoph W. Kayser², Markus Klapper ${ }^{1}$ \\ 1: Max Planck Institute for Polymer Research, Ackermannweg 10, 55128 Mainz, Germany \\ 2: Clariant Produkte (Deutschland) $\mathrm{GmbH}$, Industriepark Höchst G 860, 65926 Frankfurt, \\ Germany
}

Correspondence to: Lena Petrozziello (E-mail: lena.petrozziello@clariant.com)

\begin{abstract}
With a bifunctional symmetric RAFT agent well-defined polymer structures can be achieved. This paper shows the possibility to synthesize block copolymer systems consisting out of different activated monomers. With the novel bifunctional symmetric RAFT agent water-born polymer systems with a block structure (B- $b-\mathrm{A}-b-\mathrm{B})$ can be polymerized. The symmetric RAFT agent is designed to polymerize both more activated monomers $(A)$ and less activated monomers $(B)$. Due to the ability of a controlled radical polymerization of different activated monomers the dispersity of the resulting polymers is broader compared to common RAFT polymerizations. In regard to industrial applications like emulsifiers, stabilizers or viscosity modifiers the broader molecular weight distribution has no impact. Overall, this paper shows the possibility towards new functional polymers with unique properties.
\end{abstract}

KEYWORDS: bifunctional symmetric RAFT agent, multiblock copolymers, MAA, AA, DMAA, NVP, LAM, MAM, RAFT, Dithiocarbamat, 3,5-Dimethylpyrazol

\section{INTRODUCTION}

Polymers with well-defined block structures can combine particularly targeted physical and chemical properties to afford tailor-made systems. Their ability to microphase-separate and to assemble into defined 3D compositions [2,3] allowed their use in many industrial and biological applications [1]. The need for such structures is constantly increasing. In particular water-born block copolymer systems are very attractive from an industrial point of view and have already been used for a broad range of commercial applications such as viscosity modifiers in lubricating fluids [1,4], emulsion binders [4] or detergents for laundry treatment [5] or biological applications for drug delivery systems [3].

As a suitable technology for assembling water-born polymer systems, controlled radical polymerization (CRP) readily allow the fabrication of well-defined block copolymer structures with a variety of functionalities $[3,4]$. In the literature, different CRP techniques have been introduced. Among these, Atom Transfer Radical Polymerization (ATRP) [6,7] and Reversible AdditionFragmentation Chain Transfer Polymerization (RAFT) [1,8-10] have been applied frequently, due to their great versatility towards functional monomers and their ability to control the polymer architecture. Depending on the intended end-use of the polymer, each technique has limitations. The presence of transition metals like copper, nickel or iron in ATRP polymers renders them obsolete for cosmetic and biological applications [7,11]. RAFT polymers, on the other hand, may afford colored polymers owing to thiocarbonate end groups [8,12]. For water-born block copolymer systems polar monomers containing acid functional groups are very attractive. The CRP of such monomers is however limited to RAFT [1]. 
Block copolymers comprising only two different monomers $A$ and $B$ can exhibit various structures, such as $(\mathrm{A}-b-\mathrm{B}),(\mathrm{B}-b-\mathrm{A}),(\mathrm{A}-b-\mathrm{B}-b-\mathrm{A})$ or $(\mathrm{B}-b-\mathrm{A}-b-\mathrm{B})$ [13]. Depending on the desired architecture of the copolymer, not all structures can be synthesized via the same synthetic strategy [1]. Diblock copolymers can be obtained easily with common RAFT agents based on e.g. dithiobenzoates, dithiocarbamates and xanthates [8]. Multiblock copolymers like the structures (A- $b-\mathrm{B}-b-\mathrm{A})$ and (B$b-\mathrm{A}-b-\mathrm{B}$ ) can be synthesized with symmetric RAFT agents (see figure 1 and 2) based on trithiocarbonates [14]. The chain grows via insertion of incoming monomers from the center of the polymer chain. A disadvantage of this approach is the retention of the hydrolytically labile trithiocarbonate group in the middle of the multiblock copolymer structure (figure 1).

An additional hurdle towards multiblock copolymers is presented by the influenced of the activation state of the monomers. Depending on the used RAFT agent, either good control the polymerization of more activated monomers (MAMs) or less activated monomers (LAMs) is achieved. This depends on the selection of the Z-group, that controls the reactivity of the thiocarbonyl double bond [15]. Among the few available RAFT agents, pyrazol has been shown to function well as Z-group and both MAMs and LAMs have been successfully incorporated into block copolymer structures $[8,15]$.

The block copolymer can only be polymerized by starting with MAMs before introducing the LAMs [12]. If the monomer $A$ is more activated than monomer $B$, only the polymer structure $(A-b-B-b-A)$ can be obtained with common symmetric bifunctional RAFT agents based on trithiocarbonates. It is not possible to form the block structure (B-b-A-b-B). Some of these common symmetric RAFT agents are shown in figure 1.

FIGURE 1 - Common symmetric RAFT agents based on trithiocarbonates.

To overcome the described shortcomings, in this paper we report a new bifunctional symmetric RAFT agent with a Z-group that controls the reactivity of the RAFT agent to polymerize both LAMs and MAMs to synthesize multi-block copolymers with a block structure (B-b-A-b-B) (Figure 2).

Emphasis has been put on water-born multiblock copolymers containing carboxylic acid groups in an industrial applicable process. 

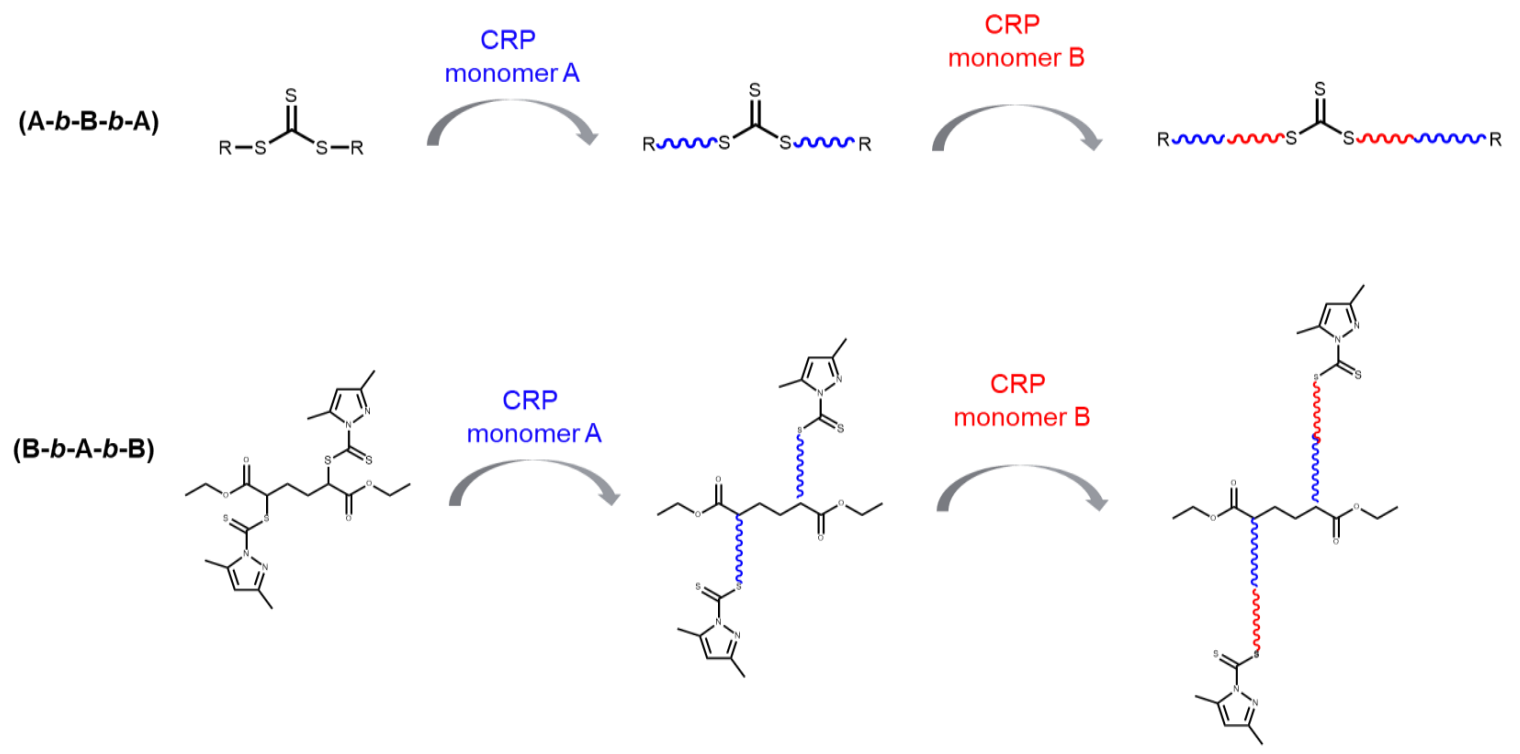

FIGURE 2 - Schematic approach of CRP of $(A-b-B-b-A)$ and (A-b-B-b-A) multiblock copolymer structures with dimethylpyrazol or xanthate as R-group. .

\section{EXPERIMENTAL}

\section{Materials}

Carbon disulfide, 3,5-dimethylpyrazol, diethyl meso-2,5-dibromoadipate, acetone, 2-propanol, methacrylic acid, acrylic acid, dimethylacryl amide, 1,3,5-trioxane were purchased from Sigma Aldrich and were used without further purification. 2,2'-Azobis[2-(2-imidazolin-2yl)propane]dihydrochloride (VA-044) was purchased from Wako chemicals. Cyanomethyl 3,5dimethylpyrazole-1-carbodithioate was purchased from Boron Molecular.

\section{Synthesis of symmetric RAFT agent}

The symmetric RAFT agent was synthesized through a nucleophilic substitution of bromine of the diethyl meso-2,5-dibromoadipate with 3,5-dimethylpyrazol and carbon disulfide according to figure 3. 3,5-dimethylpyrazol $(0.04 \mathrm{~mol}, 3.6 \mathrm{~g})$ was added to a mixture of acetone $(40 \mathrm{~mL})$ and aqueous sodium hydroxide solution $(0.06 \mathrm{~mol}, \mathrm{w}=50 \%)$ at $3-5^{\circ} \mathrm{C}$. At $3-5^{\circ} \mathrm{C}$, carbon disulfide $(0.05 \mathrm{~mol}, 3.95 \mathrm{~g})$ dissolved in acetone $(20 \mathrm{~mL})$ was added dropwise. The yellowish reaction mixture was stirred for $12 \mathrm{~h}$ at room temperature. Diethyl meso-2,5-dibromoadipate $(0.02 \mathrm{~mol}$, $8.07 \mathrm{~g})$ dissolved in acetone $(20 \mathrm{~mL})$ was added within $20 \mathrm{~min}$. The reaction mixture was cooled with a water bath. After stirring for $12 \mathrm{~h}$ the reaction mixture was concentrated to dryness. For purification, the product was dissolved in water. The acidified water phase was extracted twice with ethyl acetate $(40 \mathrm{~mL})$. The combined organic layers were washed with water, dried over sodium sulfate and the solvent was evaporated. $[13,15,16]$ The corresponding reaction scheme is shown in figure 3 .

HRMS $(m / z)$ : calcd for $\mathrm{C}_{22} \mathrm{H}_{30} \mathrm{~N}_{4} \mathrm{O}_{4} \mathrm{~S}_{4}, 542.11$; found, $543.12[\mathrm{M}+\mathrm{H}]^{+}$.

${ }^{1} \mathrm{H}$ NMR (400 MHz, $\left.\mathrm{CDCl}_{3}, \delta\right): \delta 6.09$ (s, 2H), 3.93 (qd, J = 6.3, $\left.2.2 \mathrm{~Hz}, 4 \mathrm{H}\right), 3.27$ (tt, J = 4.3, 1.9 $\mathrm{Hz}, 2 \mathrm{H}), 2.41(\mathrm{~m}, 2 \mathrm{H}), 2.28(\mathrm{~s}, 6 \mathrm{H}), 2.18(\mathrm{~m}, 2 \mathrm{H}), 2.16(\mathrm{~s}, 6 \mathrm{H}), 0.90(\mathrm{~m}, 6 \mathrm{H})$. 
${ }^{13} \mathrm{C}$ NMR (100 MHz, $\left.\mathrm{CDCl}_{3}, \delta, \mathrm{ppm}\right): 13.6\left(\mathrm{CH}_{3}\right), 14.2\left(\mathrm{CH}_{3}\right), 17.3\left(\mathrm{OCH}_{2} \mathrm{CH}_{3}\right), 28.8\left(\mathrm{CH}_{2} \mathrm{CH}_{2}\right)$, $52.1(\mathrm{CHS}), 61.8\left(\mathrm{OCH}_{2} \mathrm{CH}_{3}\right), 113.6(\mathrm{C}=\mathbf{C H}), 145.9\left(\mathrm{CNCH}_{3}\right), 152.1\left(\mathbf{C}=\mathrm{NCH}_{3}\right), 170.6(\mathrm{C}=\mathrm{O})$, $198.3(\mathrm{C}=\mathrm{S})$.

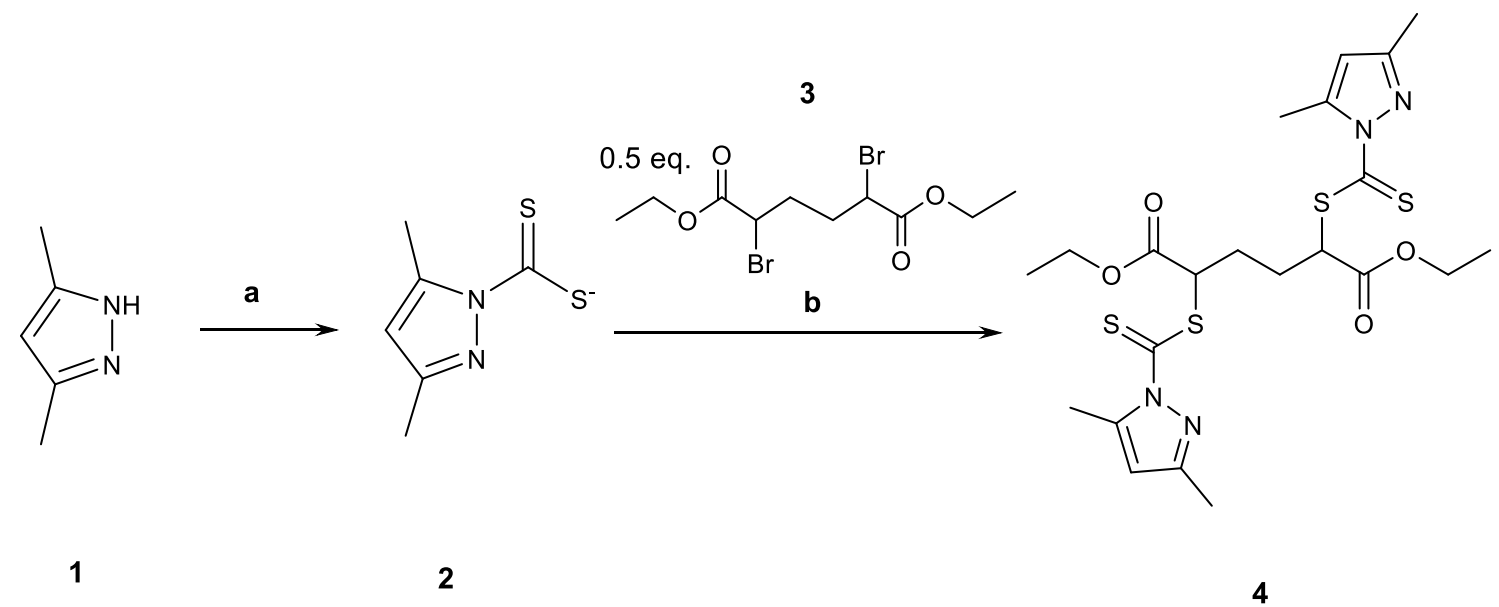

FIGURE 3 - Reaction scheme to afford the symmetric RAFT agent 4 . The reaction conditions are: (a) $\mathrm{NaOH}$, acetone, $\mathrm{CS}_{2}, 3-5^{\circ} \mathrm{C}$, dosage $20 \mathrm{~min}$ and $12 \mathrm{~h}$ at room temperature; (b) diethyl meso2,5-dibromoadipate (3), acetone, $20-25^{\circ} \mathrm{C}, 12 \mathrm{~h}$.

\section{RAFT polymerization}

In a two-necked round-bottom flask, acrylic acid (AA) $(28 \mathrm{mmol}, 2 \mathrm{~g})$ and RAFT agent 4 (0.4 mmol, $224 \mathrm{mg}$ ) were dissolved in $18 \mathrm{~g}$ of water and $6 \mathrm{~g}$ of 2-propanol. $0.35 \mathrm{mg}$ of 1,3,5-trioxane was added as internal reference for NMR analysis. After deoxygenation by evacuation and nitrogen purge the resulting mixture was heated to $60^{\circ} \mathrm{C}$ and initiated with the radical initiator 2,2'-Azobis[2(2-imidazolin-2-yl)propane] dihydrochloride $(13.3 \mathrm{mg}, 0.04 \mathrm{mmol})$. For determination of conversion and molecular weight, samples were taken after $15 \mathrm{~min}, 30 \mathrm{~min}, 60 \mathrm{~min}$ and $120 \mathrm{~min}$ and analyzed via ${ }^{1} \mathrm{H}$ NMR and SEC. The conversion was determined by comparing the signal of 1,3,5-trioxane at $\delta=5.13 \mathrm{ppm}$ to the signals of the double bond of the residual monomer. [17]

The controlled radical polymerization (CRP) with the symmetric RAFT agent was also investigated for the monomers methacrylic acid (MAA), N,N-dimethylacrylamide (DMAA) and $\mathrm{N}$ Vinylpyrrolidone (NVP). The corresponding NMR shifts are listed below.

The amount of monomer for $\mathrm{P}(\mathrm{MAA})$ was $23 \mathrm{mmol}, 2 \mathrm{~g}$, for $\mathrm{P}(\mathrm{DMAA})$ was $20 \mathrm{mmol}, 2 \mathrm{~g}$ and for $\mathrm{P}(\mathrm{NVF}) 28 \mathrm{mmol}, 2 \mathrm{~g}$.

The in table 1 listed chemical shifts of the monomers were used for determination of the conversion against the internal standard 1,3,5-trioxane. 
TABLE $1{ }^{1} \mathrm{H}$ NMR chemical shifts of monomers for determination conversion $(400 \mathrm{MHz}$, DMSO-$\left.d_{6}, \delta\right)$

\begin{tabular}{|c|c|}
\hline Monomer & $\delta[\mathrm{ppm}]^{\mathrm{a}}$ \\
\hline AA & $6.10(\mathrm{dd}, J=17.3,10.3 \mathrm{~Hz}, 2 \mathrm{H}$ \\
\hline MAA & $5.62(\mathrm{p}, J=1.6 \mathrm{~Hz}, 1 \mathrm{H})$ \\
\hline DMAA & $6.11(\mathrm{dd}, J=16.7,2.3 \mathrm{~Hz}, 2 \mathrm{H})$ \\
\hline NVP & $4.41(\mathrm{~m}, 2 \mathrm{H})$ \\
\hline
\end{tabular}

\section{RAFT block copolymerization}

RAFT polymerizations affording triblock copolymers with the block structure (B- $b-\mathrm{A}-b-\mathrm{B})$ were investigated subsequently. The following triblock copolymers were studied: P(DMAA- $b-A A-b-$ DMAA) and P(NVP-b-DMAA- $b-N V P)$.

In a two-necked round-bottom flask $25 \mathrm{mmol}$ of monomer A and $0.4 \mathrm{mmol}$ of RAFT agent 4 were dissolved in $18 \mathrm{~g}$ of water and $6 \mathrm{~g}$ of 2-propanol. $0.35 \mathrm{mg}$ of 1,3,5-trioxane was added as internal reference for NMR analysis. After deoxygenation by evacuation and nitrogen purge, the resulting mixture was heated to $60^{\circ} \mathrm{C}$ and initiated with the radical initiator 2,2'-Azobis[2-(2-imidazolin-2yl)propane] dihydrochloride (VA-044) $(13.3 \mathrm{mg}, 0.04 \mathrm{mmol})$. After the synthesis of block A, 250 $\mathrm{mmol}$ of monomer $\mathrm{B}$ was added and re-initiated with $0.04 \mathrm{~mol}$ VA-044. For determining conversion and molecular weight, samples were taken after $15 \mathrm{~min}, 30 \mathrm{~min}, 60 \mathrm{~min}$ and $120 \mathrm{~min}$ for each block and analyzed via ${ }^{1} \mathrm{H}$ NMR and SEC. The conversion was determined by comparing the signal of $1,3,5$-trioxane at $\delta=5.13 \mathrm{ppm}$ relatively to the signals of the double bond of each investigated monomer (s. table 1). [17]

\section{Analytical Characterization}

\section{HRMS Measurement}

4 (5 mg) was dissolved in $10 \mathrm{~mL}$ of methanol and diluted 1:100 in methanol. The HRMS measurement was performed with an Ultimate-HPLC - Q Exactive Focus system of Thermo Scientific.

\section{NMR Measurement}

4 (20 mg) was dissolved in $0.5 \mathrm{~mL}$ chloroform- $\mathrm{d}_{1}\left(\mathrm{CDCl}_{3}\right.$; Merck). Polymer samples (200 mg) for reaction control were dissolved in DMSO- $\mathrm{d}_{6} .{ }^{1} \mathrm{H}$ NMR and ${ }^{13} \mathrm{C}$ NMR were recorded with a 400 $\mathrm{MHz}$ (Bruker) spectrometer.

\section{SEC Measurement}

The molecular weight distribution was determined via size exclusion chromatography (SEC). The polymer solution $(5 \mathrm{mg} / \mathrm{mL})$ was dissolved in eluent and measured via SUPREMA SEC columns from PSS using an Agilent 1100 chromatography system with a refractive index and UV detector. The molecular weight was determined using Polyacrylic acid (PAA) samples as molecular weight standards. 

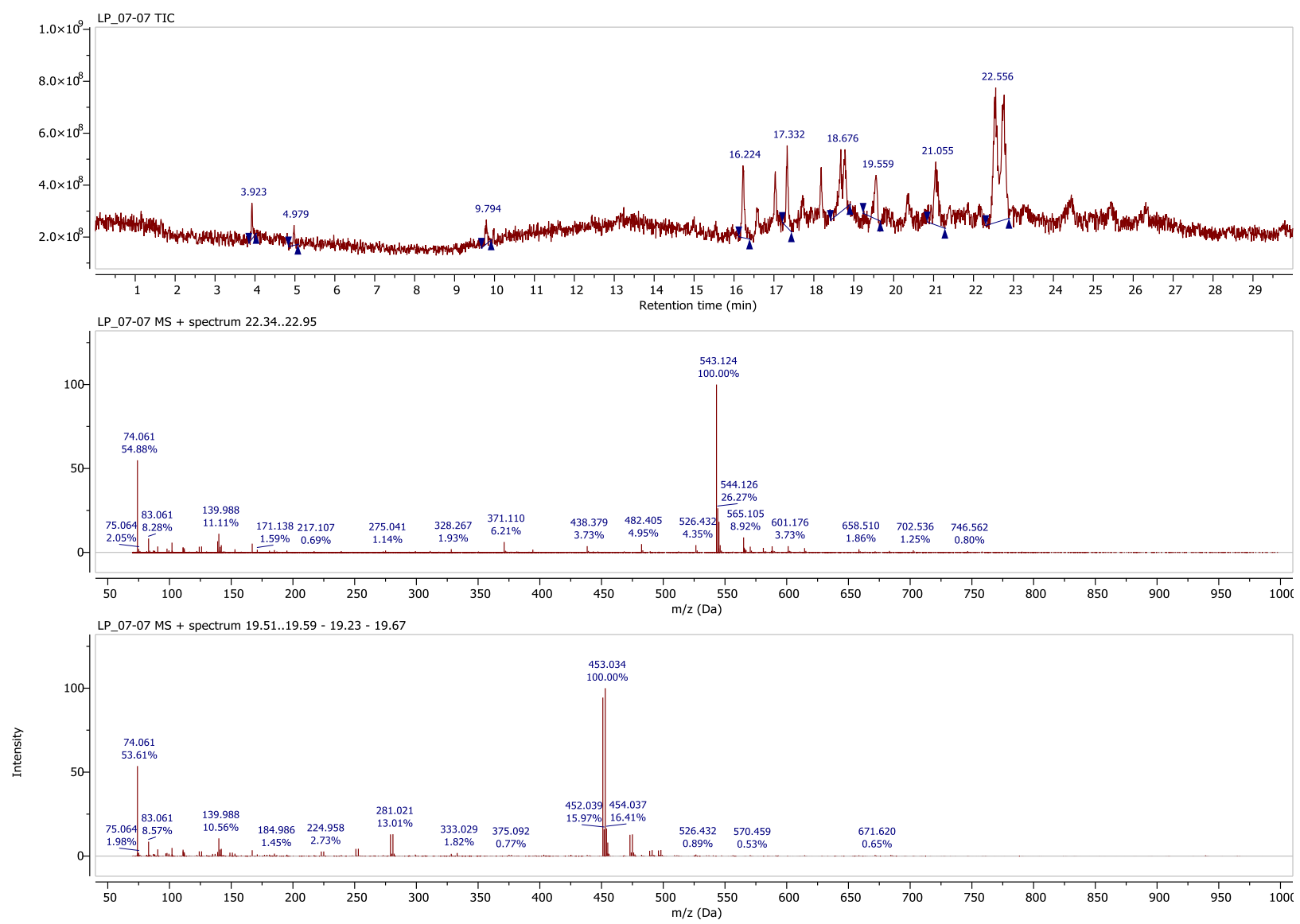

FIGURE 4 HRMS spectra of symmetric RAFT agent 4 at 22.55 min retention time and single substituted by-product at 19.55 min retention time. HRMS $(\mathrm{m} / \mathrm{z})$ : calcd for $\mathrm{C}_{22} \mathrm{H}_{30} \mathrm{~N}_{4} \mathrm{O}_{4} \mathrm{~S}_{4}, 542.11$; found, $543.12[\mathrm{M}+\mathrm{H}]^{+}$. HRMS $(\mathrm{m} / \mathrm{z})$ : calcd for $\mathrm{C}_{16} \mathrm{H}_{23} \mathrm{BrN}_{2} \mathrm{O}_{4} \mathrm{~S}_{2}, 450.03$; found, $453.03[\mathrm{M}+\mathrm{H}]^{+}$.

A water/acetonitrile mixture $(80: 20$ vol\%) containing $0.035 \mathrm{~mol} / \mathrm{L}$ di-sodium hydrogen phosphate was used as eluent. The measurement was performed at $23^{\circ} \mathrm{C}$ with a flow rate of $1 \mathrm{~mL} / \mathrm{min}$. 


\section{RESULTS AND DISCUSSION}

\section{Synthesis of symmetric RAFT agent}

For obtaining the desired triblock copolymer structures (B-b-A-b-B) with MAMs $(A)$ and LAMs (B), RAFT agent 4 was required. Typical symmetric RAFT agents, as shown in figure 1 with trithiocarbonate structures, only results in the polymer structure (A-b-B-b-A). 3,5-dimethylpyrazol was chosen as Z-group because pyrazole derivates belong to the limited group of substituents which can polymerize both LAMs and MAMs [16].

The symmetric RAFT agent diethyl 2,5-bis((3,5-dimethylpyrazole-1-carbonothioyl)thio) hexanedioate 4 was synthesized in a two-step reaction. In the first step, the carbodithioate nucleophile was synthesized, which ultimately forms the Z-group of the RAFT agent. 3,5dimethylpyrazol was chosen as Z-group due to its ability to control the reactivity of the thiocarbonylthio group in a fashion that both MAMs and LAMs could be polymerized [8].

The second step was the nucleophilic substitution with the central block of the RAFT agent. The structure of the RAFT agent was designed so that the diethyl meso-2,5-dibromoadipate forms the central block and the reversible chain-transfer process of the thiocarbonylthio group proceeded at the chain ends of the polymer. [15,16]

The structural characterization of the synthesized RAFT agent was confirmed by HRMS and ${ }^{13} \mathrm{C}$ NMR. The spectra are shown in figure 4, 5 and 6 . The symmetric RAFT agent 4 could be synthesized with a conversion of $63 \%$ as determined via HRMS. Next to non-converted products the mono substituted by-product was present with $6 \%$. For further characterization and application in polymerizations, the reaction product was purified via extraction. After this purification only less than $1 \%$ of the mono substituted by-product was found in the symmetric RAFT agent 4. The non-converted products were eliminated through the purification step due to their higher water solubility.
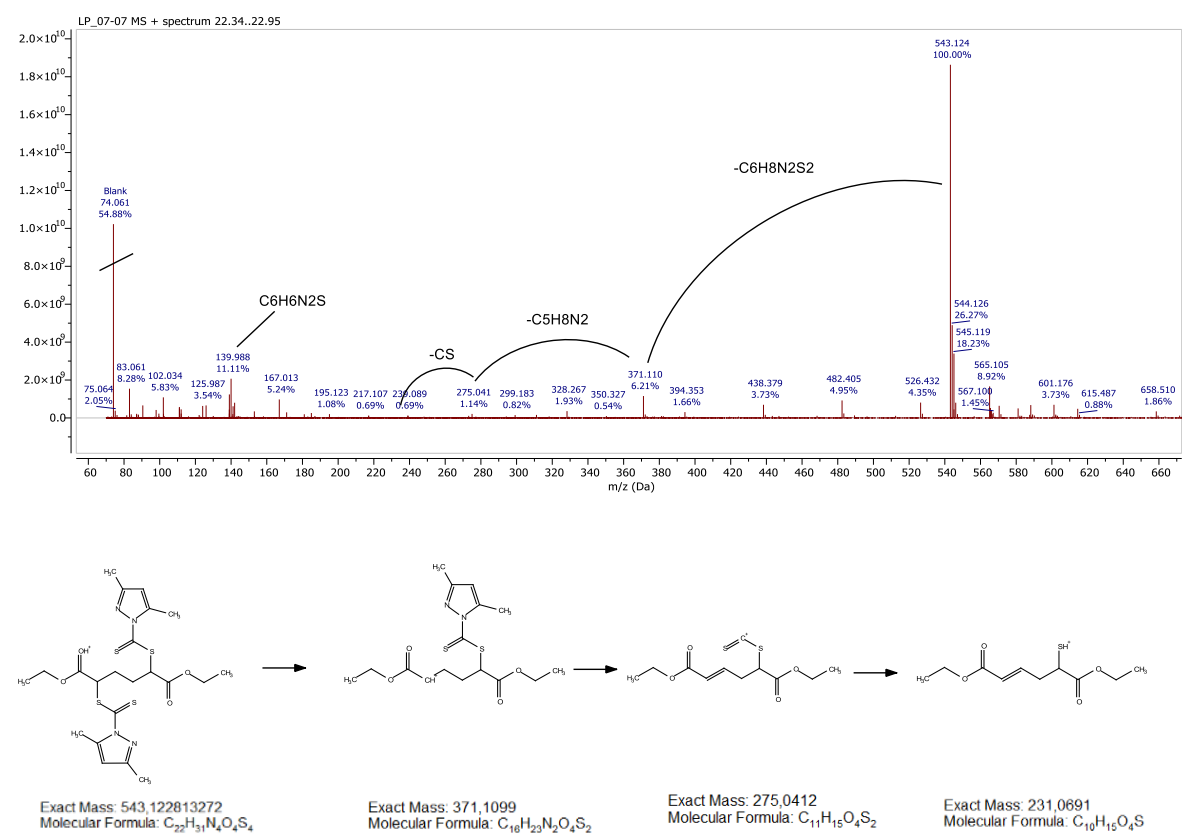

FIGURE 5 - HRMS Fragmentation mechanism of symmetric RAFT agent 4. HRMS $(\mathrm{m} / \mathrm{z})$ : calcd for $\mathrm{C}_{22} \mathrm{H}_{30} \mathrm{~N}_{4} \mathrm{O}_{4} \mathrm{~S}_{4}, 542.11$; found, $543.12[\mathrm{M}+\mathrm{H}]^{+}$. 
In figure 5 the fragmentation mechanism of the symmetric RAFT agent $\mathbf{4}$ is shown as proof of the synthesized symmetric structure. Figure 6 shows the ${ }^{13} \mathrm{C}$ NMR spectra of symmetric RAFT agent 4 with structure assignment of the obtained signals. In conclusion, the synthetic route chosen for obtaining the bifunctional, symmetric RAFT agent $\mathbf{4}$ was successful. This could be proven by the analytical data shown in figure 5 and 6.

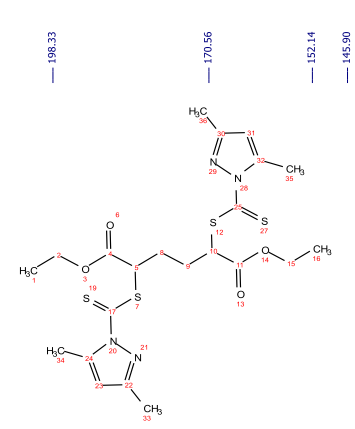

23,31
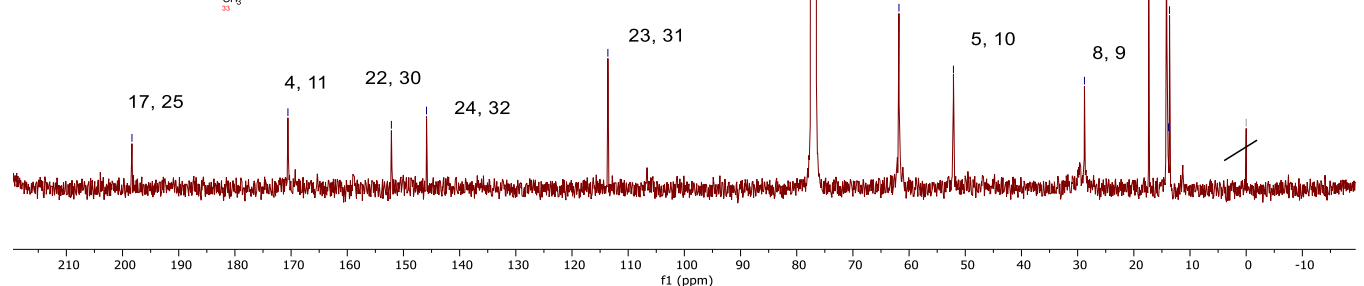

FIGURE $6-{ }^{13} \mathrm{C}$ NMR spectra of symmetric RAFT agent. ${ }^{13} \mathrm{C}$ NMR $\left(400 \mathrm{MHz}, \mathrm{CDCl}_{3}, \delta, \mathrm{ppm}\right): 13.6$ $\left(\mathrm{CH}_{3}\right), 14.2\left(\mathrm{CH}_{3}\right), 17.3\left(\mathrm{CH}_{2} \mathrm{CH}_{3}\right), 28.8\left(\mathrm{CH}_{2} \mathrm{CH}_{2}\right), 52.1(\mathrm{CHS}), 61.8\left(\mathrm{OCH}_{2} \mathrm{CH}_{3}\right), 113.6(\mathrm{C}=\mathrm{CH}), 145.9$ $\left(\mathrm{CNCH}_{3}\right), 152.1\left(\mathrm{CNCH}_{3}\right), 170.6(\mathrm{C}=\mathrm{O}), 198.3(\mathrm{C}=\mathrm{S})$.

(1)

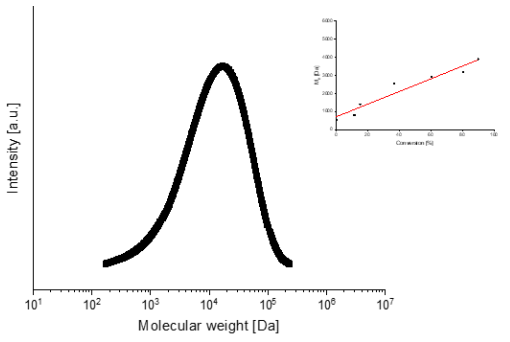

(2)

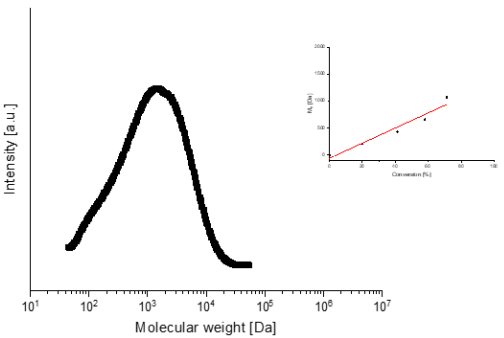

(3)

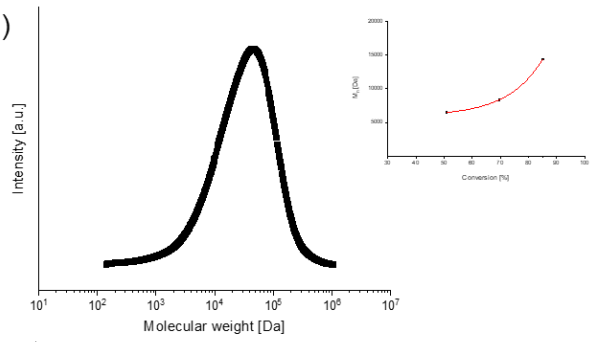

(4)

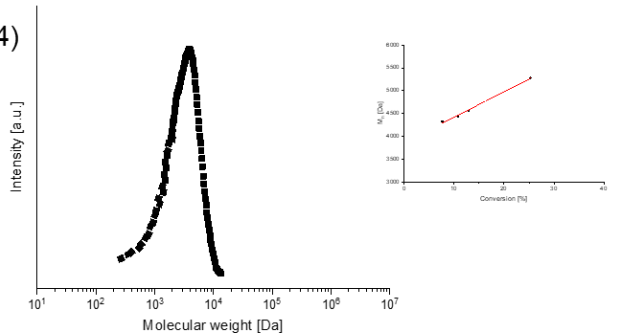

FIGURE 7 - Molecular weight distribution of the CRP with the symmetric RAFT agent 4 of AA (1), DMAA (2), MAA (3) and NVP (4) correlated with chain growth and conversion profile. The molecular weight is determined relative to PAA standards. 


\section{Controlled Radical Polymerization}

\section{Homo-Polymerization of MAMs and LAMs}

DMAA, AA and MAA as MAMs and NVP as LAMs were polymerized in aqueous solution with the symmetric RAFT agent diethyl 2,5-bis((3,5-dimethylpyrazole-1-carbonothioyl)thio)hexanedioate 4. The theoretical number average molecular weight $M_{n, t h}$ can be calculated using the simplified equation 1, where $[\mathrm{M}]_{0}$, [RAFT] 0 are the initial concentrations of monomer (M) and RAFT agent (RAFT), $p$ is the monomer conversion and $M_{\text {RAFT }}$ and $M_{M}$ are the molar masses of each component $[8,13]$.

$$
M_{n, t h}=\frac{[M]_{0} p M_{M}}{[R A F T]_{0}}+M_{R A F T}
$$

In table 2, both measured and theoretical number average molecular weight $M_{n}$ and $M_{n, t h}$, the conversion and the polydispersity index (Đ) are shown. The corresponding molecular weight distributions are shown in figure 7.

TABLE 2 Results of CRP of DMAA, AA, MAA and NVP with the symmetric RAFT agent

\begin{tabular}{lllll}
\hline Monomer & $\begin{array}{l}\text { Conversion } \\
{[\%]^{\mathrm{a}}}\end{array}$ & $\mathrm{M}_{\mathrm{n}, \mathrm{th}}[\mathrm{Da}]$ & $\mathrm{M}_{\mathrm{n}}[\mathrm{Da}]^{\mathrm{b}}$ & $\bigoplus$ \\
\hline AA & 90 & 5,000 & 4,900 & 2.8 \\
\hline DMAA & 71 & 4,100 & 1,100 & 2.5 \\
MAA & 84 & 4,700 & 14,400 & 4.0 \\
\hline NVP & 25 & 5,600 & 5,300 & 1.3 \\
$\begin{array}{l}\text { a Determined with }{ }^{1} \mathrm{H}-\mathrm{NMR} \text { spectroscopy. } \\
\text { b Determined with SEC relative to PAA standards. }\end{array}$
\end{tabular}

The polymerization of the MAMs AA and DMAA as well as of the LAM NVP showed a good control during the polymerization. AA, DMAA and NVP showed a linear correlation between molecular weight increase and conversion, which proofs a controlled radical polymerization. As expected, all these monomers could undergo a controlled radical polymerization $[8,16]$.

A good match of the measured and theoretical number average molecular weight $M_{n}$ and $M_{n, t h}$ for AA and NVP could be observed. Only the conversion of NVP is with $25 \%$ very low. This is caused by the fact of a less activated monomer which has a slower reaction rate. The conversion of DMAA was $71 \%$ and a linear fit could be shown between conversion and molecular weight. However the measured and theoretical number average molecular weight $M_{n}$ and $M_{n, t h}$ didn't fit together. The low $M_{n}$ of 1,100 Da could be an artefact of SEC measurement, which was conducted relative to PAA standards. Due to different hydrodynamic volumina the measured $M_{n}$ could be underestimated.

Compared to other common CRP polymers, the molecular weight distributions were broader ( $\boxminus$ $>2$ ). This was caused by the Z-group and the bifunctional symmetric RAFT agent. 3,5dimethylpyrazol as Z-group has the advantage to control the polymerization of different activated monomers LAMs and MAMs with the sacrifice of a very narrow molecular weight distribution. In addition, the chain growth on two sides of the RAFT agent may cause an independent chain growth. This results in a slightly broader dispersity as well. In addition, the polymerization was done without purification of solvents to operate under industrial conditions. Hence comprising stabilizer could cause the broader dispersity as well. 
Only MAA showed a high molecular weight with $14 \mathrm{kDa}$. In addition, the high PDI of 4.0 showed that the polymerization of MAA did not occur as CRP. This is caused by the fact, that MAA upon reacting with an initiator radical, forms a $3^{\circ}$ radical, which might add to the thiocarbonyl double bond of the RAFT agent. However, this $3^{\circ}$ is a better leaving compared to the $2^{\circ}$ radical of the RAFT agent and thus a controlled polymerization is not possible.

To understand the influence of 3,5-dimethylpyrazol as Z-group on the dispersity of the RAFT polymers, monomer AA was polymerized with the one-side active RAFT agent cyanomethyl 3,5dimethylpyrazole-1-carbodithioate and without RAFT agent.

The two CRP syntheses were compared with the free radical polymerization (FRP) of AA. The molecular weight distributions by SEC are shown in figure 8 . The corresponding data are listed in table 3.

TABLE 3 Results comparison of polymerization of AA via FRP and CRP with different RAFT agents.

\begin{tabular}{llllll}
\hline Monomer & RAFT & $\begin{array}{l}\text { Conversion } \\
{[\%]^{a}}\end{array}$ & $\mathrm{M}_{\mathrm{n}, \mathrm{th}}[\mathrm{Da}]$ & $\mathrm{M}_{\mathrm{n}}[\mathrm{Da}]^{\mathrm{b}}$ & $\boxminus$ \\
\hline AA - CRP & 4 & 90 & 5,000 & 4,900 & 2.8 \\
\hline AA - CRP & 5 & 93 & 2,500 & 2,400 & 2.9 \\
\hline AA - FRP & - & 44 & n.a. & 83,000 & 4.9 \\
\hline
\end{tabular}

a Determined with ${ }^{1} \mathrm{H}-\mathrm{NMR}$ spectroscopy.

${ }^{b}$ Determined with SEC relative to PAA standards.

Both CRP approaches showed a $\boxminus$ of $>2$. The FRP of AA resulted in a significantly broader molecular weight distribution $(\Xi=4.4)$. Therefore, both RAFT agents based on 3,5dimethylpyrazol showed a controlled chain growth compared to the FRP approach. Accordingly, the broader $\boxminus$ of more than 2 compared to standard CRP approaches was caused by this particular Z-group. In addition, the high $Đ$ might be caused by the SEC method itself by interaction of the polymer with the column material.

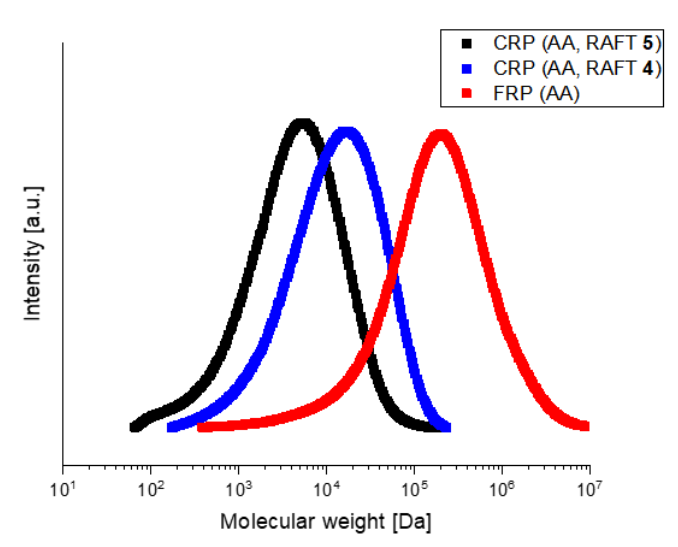

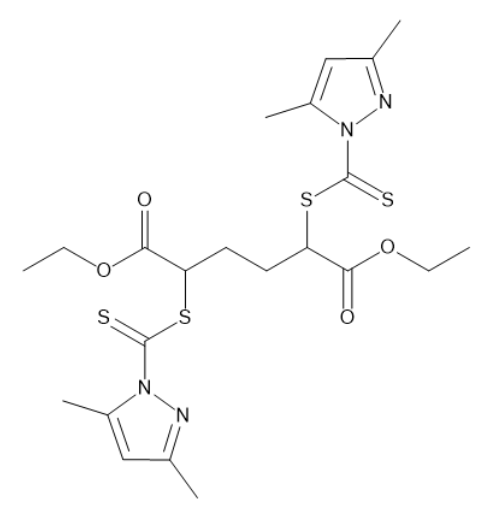

symmetric RAFT agent 4

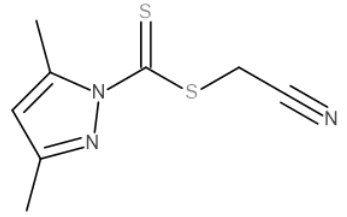

RAFT agent 5

FIGURE 8 - Molecular weight distribution of the polymerization of AA with symmetric RAFT agent diethyl 2,5-bis((3,5-dimethylpyrazole-1-carbonothioyl)thio)hexanedioate 4, one-side active RAFT agent cyanomethyl 3,5-dimethylpyrazole-1-carbodithioate 5 and FRP. The molecular weight is determined relative to PAA. 


\section{Synthesis of triblock copolymer structures}

According to the CRP results of the selected MAMs and LAMs, different triblock copolymer structures were synthesized with the new symmetric RAFT agent 4.

The results of the CRP are shown in table 4.

TABLE 4 Results CRP of triblock copolymers.

\begin{tabular}{lllll}
\hline Monomer & $\begin{array}{l}\text { Conversion } \\
{[\%]^{\mathrm{a}}}\end{array}$ & $\begin{array}{l}\mathrm{M}_{\mathrm{n}, \mathrm{h}} \\
{[\mathrm{Da}]}\end{array}$ & $\mathrm{M}_{\mathrm{n}}{\text { [Da }]^{\mathrm{b}}}^{\mathrm{Ð}}$ & \\
\hline AA - DMAA & 40 & 13,900 & 4,500 & 3.1 \\
\hline DMAA - NVP & 32 & 14,000 & 3,100 & 2.7
\end{tabular}

${ }^{\text {a }}$ Determined with ${ }^{1} \mathrm{H}-\mathrm{NMR}$ spectroscopy.

${ }^{b}$ Determined with SEC relative to PEG standards.

The SEC analysis of the triblock copolymers P(DMAA- $b$-AA- $b$-DMAA) and P(NVP- $b$-DMAA- $b$ NVP) showed an increase in molecular weight following the addition of monomer $B$, although the conversion of monomers was only below $50 \%$. Comparison of the measured molecular weight $M_{n}$ and the theoretical number average $M_{n, t h}$ showed no good match. The low measured molecular weight $\mathrm{M}_{\mathrm{n}}$ could be an artefact due to the SEC measurement. Therefore, as a proof of the successful polymerization affording the desired triblock copolymer structure, the diffusion-ordered spectroscopy (DOSY) NMR spectra are shown below. The corresponding chemical shifts of the monomers are analyzed. The red labeled signals of monomer A show the same diffusion coefficient as monomer B (blue labeled) within the polymer area (black labeled) with a diffusion coefficient of about $10^{-11.0} \pm 0.5$. Accordingly, only one polymer species is obtained.

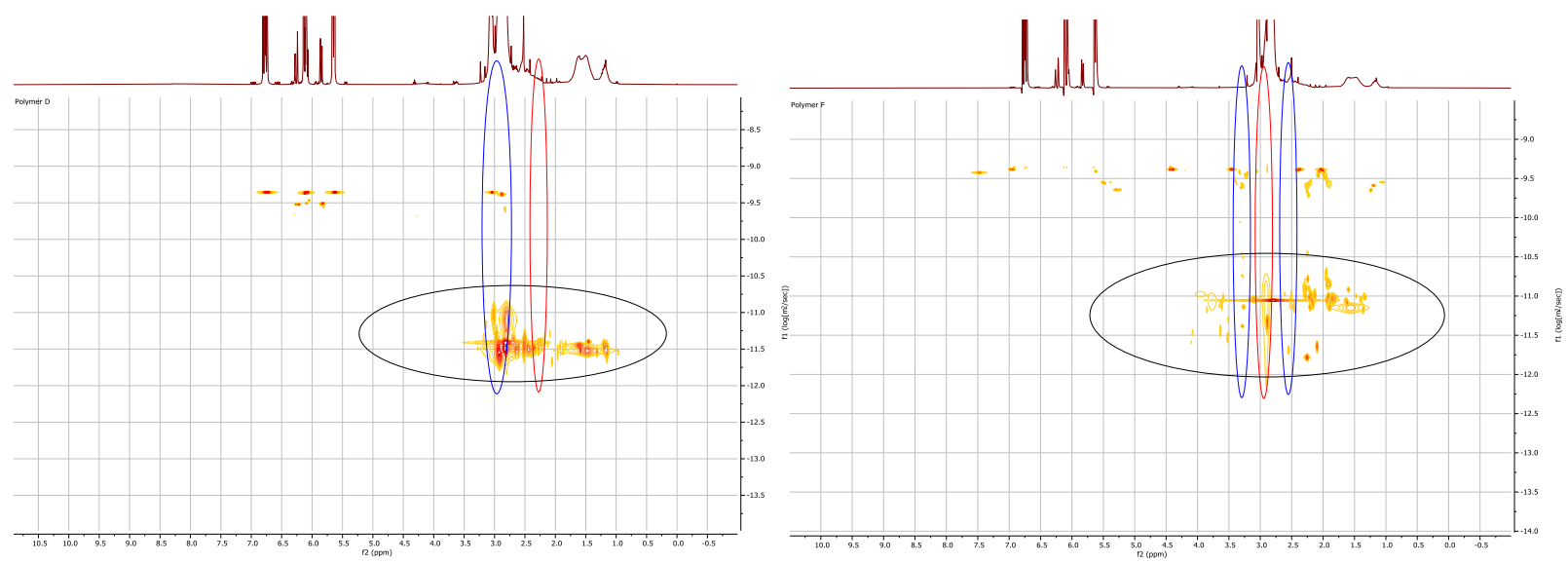

FIGURE 9 - DOSY NMR spectra of triblock copolymers P(DMAA-b-AA-b-DMAA) (left) and $\mathrm{P}(\mathrm{NVP}-b$-DMAA- $b$-NVP) (right) with blue labeled chemical shift of monomer $\mathrm{A}$ and red labeled chemical shift of monomer B in area of diffusion coefficient of polymeric species (black labeled). 


\section{CONCLUSIONS}

The controlled radical polymerization of monomers with different activation states can be performed successfully using the symmetric RAFT agent diethyl 2,5-bis((3,5-dimethylpyrazole-1carbonothioyl)thio)hexanedioate.

Depending on the selection of monomers, the Z-group can be chosen from the different classes of RAFT agents such as dithiocarbamates, trithiocarbonates or xanthates. The investigated symmetric RAFT agent 4 is selected from the class of dithiocarbamates with 3,5-dimethylpyrazol as stabilizing group.

This RAFT agent containing 3,5-dimethylpyrazol successfully stabilizes the adduct radical to control the polymerization of both more activated (MAM) and less activated monomers (LAM). The ability to stabilize both MAMs and LAMs during RAFT polymerization comes at the cost of a broader molecular weight distribution which is caused by the two-side active symmetric RAFT agent and 3,5-dimethylpyrazol as Z-group. The novel RAFT agent $\mathbf{4}$ is not suitable for methacrylates.

The desired triblock copolymer structures using the monomer toolbox of AA, NVP and DMAA could be synthesized successfully, as shown by the DOSY NMR spectra. The new, symmetric RAFT agent enables the polymerization of multiblock copolymers with the block structure (B-b-A$b$-B), in which less activated monomers are located at the ends of the polymer chains. It thus complements the polymer chemist's toolbox and paves the way towards new functional polymers with unique properties. Such triblock copolymers then can be used in a wide variety of applications, for example as associative thickeners, stabilizers or dispersing agents.

\section{ACKNOWLEDGEMENTS}

We would like to acknowledge Clariant Produkte Germany GmbH for facilitating this research.

\section{REFERENCES AND NOTES}

[1] Moad G, Rizzardo E, Thang SH. RAFT polymerization and some of its applications. Chem Asian J 2013;8(8):1634-44. https://doi.org/10.1002/asia.201300262.

[2] Schacher FH, Rupar PA, Manners I. Funktionale Blockcopolymere: Nanostrukturierte Materialien mit neuen Anwendungsmöglichkeiten. Angew. Chem. 2012;124(32):8020-44. https://doi.org/10.1002/ange.201200310.

[3] Agrahari V, Agrahari V. Advances and applications of block-copolymer-based nanoformulations. Drug Discov Today 2018;23(5):1139-51. https://doi.org/10.1016/j.drudis.2018.03.004.

[4] Destarac M. Industrial development of reversible-deactivation radical polymerization: Is the induction period over? Polym. Chem. 2018;9(40):4947-67. https://doi.org/10.1039/C8PY00970H.

[5] Blokzijl W, Carswell RJ, Charmot D, Hunter RA, Liu M, Mansky P. Laundry Treatment Composition(US 2004/0121938 A1); 2002.

[6] Matyjaszewski K, Tsarevsky NV. Nanostructured functional materials prepared by atom transfer radical polymerization. Nat Chem 2009;1(4):276-88.

https://doi.org/10.1038/nchem.257.

[7] Matyjaszewski K. Atom Transfer Radical Polymerization: From Mechanisms to Applications. Isr. J. Chem. 2012;52(3-4):206-20. https://doi.org/10.1002/ijch.201100101. 
[8] Perrier S. 50th Anniversary Perspective: RAFT Polymerization-A User Guide. Macromolecules 2017;50(19):7433-47. https://doi.org/10.1021/acs.macromol.7b00767.

[9] Thierry Senninger, Laurent Sanchez, Vincent Darcos, Dominique Lastecoueres, JeanBaptiste Verlhac. Process for the controlled radical polymerization or copolymerization of (meth)acrylic, vinyl, vinylidene and diene monomers, and (co)polymers obtained(US 5854364 A).

[10] Rizzardo E, Solomon DH. On the Origins of Nitroxide Mediated Polymerization (NMP) and Reversible Addition-Fragmentation Chain Transfer (RAFT). Aust. J. Chem. 2012;65(8):945. https://doi.org/10.1071/CH12194.

[11] Qiu J, Charleux B, Matyjaszewskia K. Controlled/living radical polymerization in aqueous media: homogeneous and heterogeneous systems. Progress in Polymer Science $2001 ; 2001(26): 2083-134$.

[12] Destarac M. Controlled Radical Polymerization: Industrial Stakes, Obstacles and Achievements. Macromol. React. Eng. 2010;4(3-4):165-79. https://doi.org/10.1002/mren.200900087.

[13] Keddie DJ. A guide to the synthesis of block copolymers using reversible-addition fragmentation chain transfer (RAFT) polymerization. Chem Soc Rev 2014;43(2):496-505. https://doi.org/10.1039/c3cs60290g.

[14] Wang R, McCormick CL, Lowe AB. Synthesis and Evaluation of New Dicarboxylic Acid Functional Trithiocarbonates: RAFT Synthesis of Telechelic Poly(n -butyl acrylate)s. Macromolecules 2005;38(23):9518-25. https://doi.org/10.1021/ma050669w.

[15] Keddie DJ, Moad G, Rizzardo E, Thang SH. RAFT Agent Design and Synthesis. Macromolecules 2012;45(13):5321-42. https://doi.org/10.1021/ma300410v.

[16] Gardiner J, Martinez-Botella I, Tsanaktsidis J, Moad G. Dithiocarbamate RAFT agents with broad applicability - the 3,5-dimethyl-1H-pyrazole-1-carbodithioates. Polym. Chem. 2016;7(2):481-92. https://doi.org/10.1039/C5PY01382H.

[17] Chaduc I, Zhang W, Rieger J, Lansalot M, D'Agosto F, Charleux B. Amphiphilic block copolymers from a direct and one-pot RAFT synthesis in water. Macromol Rapid Commun 2011;32(16):1270-6. https://doi.org/10.1002/marc.201100240. 


\title{
GRAPHICAL ABSTRACT
}

\author{
AUTHOR NAMES \\ Lena Petrozziello, Matthias Häußler, Christoph Kayser, Markus Klapper
}

\section{TITLE}

Defined polymer structures like multiblock copolymers have an increasing impact on many applications like e.g. biomedicine, dispersants, adhesives or membranes. Through the controlled radical polymerization via the Reversible Addition/Fragmentation Chain Transfer (RAFT) technique different physical and chemical properties can be achieved within one polymer structure. To enable further symmetric block copolymer structures a novel symmetric RAFT agent is developed for polymerizing different activated monomers. 